\title{
Metode Tracer Test untuk Mencari Hubungan Antar Sistem Sungai Bawah Tanah Di Akuifer Karst
}

\author{
Harjito \\ Laboratorium Hidrologi dan Kualitas Air \\ Fakultas Geografi, Universitas Gadjah Mada, Yogyakarta \\ email : jitoo_2007@yahoo.co.id
}

\begin{abstract}
Abstrak
Problem yang umum dijumpai di kawasan karst adalah mengenai ketersediaan air, mengingat kondisi hidrologi kawasan karst yang berbeda dengan kawasan lain. Ditinjau dari sisi lain, masyarakat di sekitar kawasan rencana perluasan eksploitasi masih memanfaatkan mata air yang daerah tangkapannya berasal dari perbukitan batu gamping untuk memenuhi kebutuhan air domestik dan irigasi pertanian. Dengan demikian, perlu adanya penelitian hidrologi karst lebih lanjut terutama mengenai keberadaan sistem jaringan yang saling terhubung di dalam kawasan rencana perluasan eksploitasi dan sekitarnya. Studi ini diharapkan dapat menjadi pertimbangan terhadap kebijakan yang akan diambil sebagai upaya untuk dapat melakukan pengelolaan potensi tersebut sebaik-baiknya. Tracer test dilakukan sebagai bentuk follow-up dari survei gua dan sinkhole yang ada di sekitar area tambang. Tracer test dilakukan untuk mengetahui konektivitas aliran pada sistem gua berair dan mata air Cipintu. Berdasarkan hasil penelitian potensi debit air di Mata air Cipintu sebesar 18,55 liter/s dan mengindikasikan adanya konektivitas antara gua berair dengan Mata air Cipintu.
\end{abstract}

Kata kunci : karst, hidrologi, tracer test, eksploitasi

\section{PENDAHULUAN}

\section{Latar Belakang}

Istilah karst dan fenomenanya belum banyak dikenal luas oleh masyarakat umum, secara harfiah karst merupakan istilah dalam bahasa Jerman yang diturunkan dari bahasa Slovenia yaitu kras yang berarti lahan gersang berbatu. Istilah ini di negara asalnya sebenarnya tidak berkaitan dengan batu gamping dan proses pelarutan, namun saat ini istilah krast telah diadopsi untuk istilah bentuk lahan hasil proses pelarutan. Ford dan Williams (1989) mendefinisikan karst sebagai medan dengan kondisi hidrologi yang khas sebagai akibat dari batuan yang mudah larut dan mempunyai porositas sekunder yang berkembang baik. Problem yang umum dijumpai di Kawasan Karst adalah mengenai ketersediaan air. Mengingat kondisi hidrologi kawasan karst yang berbeda dengan kawasan lain, seperti yang diilustrasi pada Gambar 1 berikut : 


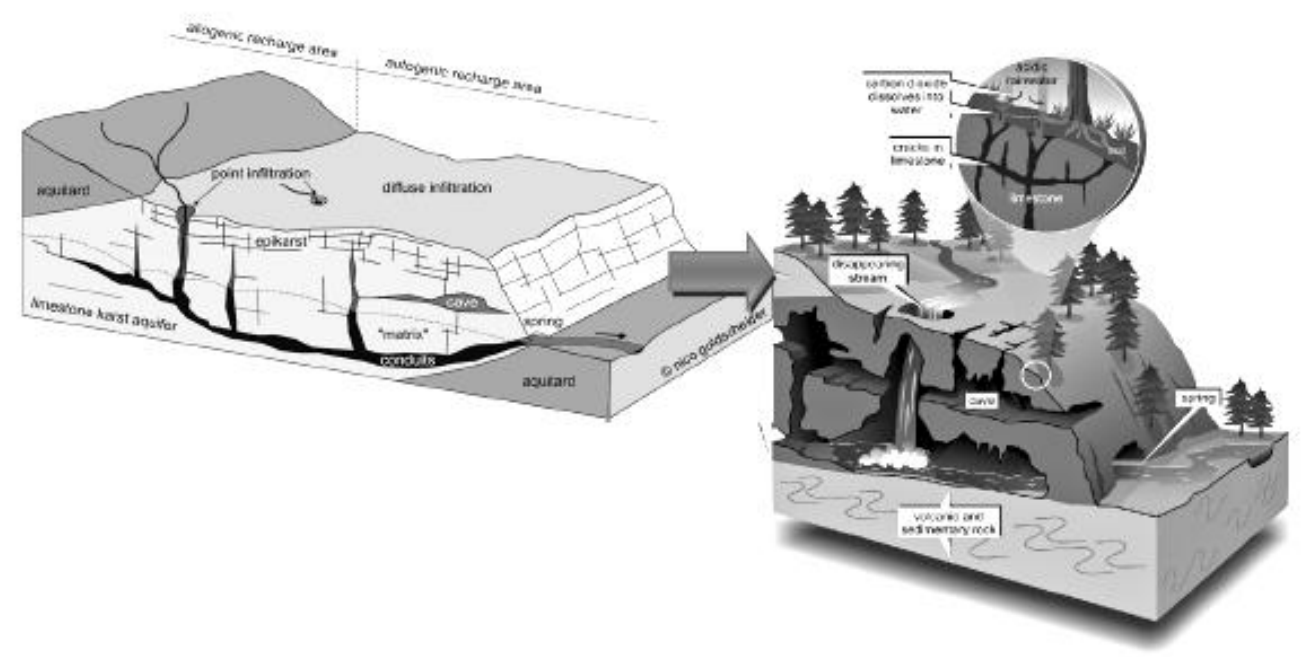

Gambar 1. Ilustrasi Sistem Hidrologi Karst (Goldscheider, 2010)

Gambar 1 terlihat bahwa sifat batuan karbonat yang mempunyai banyak rongga percelahan dan mudah larut dalam air, maka sistem drainase permukaan tidak berkembang dan lebih didominasi oleh sistem drainase bawah permukaan. Sebagai contoh langsung adalah sistem gua yang berair dan kemudian dikenal sebagai sungai bawah tanah. Secara definitif, air pada sungai bawah tanah di daerah karst boleh disebut sebagai airtanah, merujuk definisi airtanah oleh Todd (1980) bahwa airtanah merupakan air yang mengisi celah atau pori-pori atau rongga antar batuan dan bersifat dinamis. Sedangkan air bawah tanah karst juga merupakan air yang mengisi batuan atau percelahan yang banyak terdapat pada kawasan ini, walaupun karakteristiknya sangat berbeda dibandingkan dengan karakteristik airtanah pada kawasan lain.

Sebagai salah satu pertimbangan utama dalam penelitian ini adalah proses pembangunan di Indonesia yang berlangsung semakin pesat dan merata di semua wilayah diikuti dengan semakin tingginya kebutuhan semen sebagai salah satu bahan utama dalam proses pembangunan. Kebutuhan bahan baku dalam pembuatan semen berupa batu gamping juga meningkat. Oleh karenanya PT. Holcim Indonesia berusaha untuk memenuhi kebutuhan bahan baku semen dengan rencana perluasan area eksploitasi di daerah Narogong, Jawa Barat. Di mana kawasan ini memiliki perbukitan batu gamping yang potensial untuk dieksploitasi sebagai bahan baku semen.

Ditinjau dari sisi lain, masyarakat di sekitar kawasan rencana perluasan eksploitasi masih memanfaatkan mata air yang daerah tangkapannya berasal dari perbukitan batu gamping untuk memenuhi kebutuhan air domestik dan irigasi pertanian. Dengan demikian, perlu adanya penelitian hidrologi karst lebih lanjut terutama mengenai keberadaan sistem jaringan yang saling terhubung di dalam kawasan rencana perlasan eksploitasi dan sekitarnya. Studi ini diharapkan dapat menjadi 
pertimbangan terhadap kebijakan yang akan diambil sebagai upaya untuk dapat melakukan pengelolaan potensi tersebut sebaik-baiknya.

Metode Tracer Test pada aliran air dikenal secara luas sebagai salah satu cara yang dapat dipertanggungjawabkan untuk mencari hubungan antar goa atau sistem sungai bawah tanah di akuifer karst. Hal ini dilakukan oleh MacDonalds and Partners (1983) untuk melacak sistem sungai bawah tanah di karst Gunung Sewu, Yogyakarta. Hasil pelacakan tersebut sampai sekarang masing digunakan oleh pihak-pihak yang berkepentingan terhadap pengembangan sumberdaya air karst di wilayah tersebut. Metode ini secara sederhana adalah memasukkan atau menuang sesuatu pada aliran air di swallow hole atau sungai yang akan masuk ke goa, atau ponor/sinkhole dan kemudian menghadang atau menjemput pada suatu lokasi yang diperkirakan mempunyai hubungan dengan titik awal kita menuang tracer tadi. Jika tracer yang kita tuang "tertangkap" secara fisik ataupun dengan alat pengukur yang lain maka dapat dipastikan bahwa ada hubungan antara titik pertama tempat kita menuang tracer dengan titik kedua tempat kita mencegat tracer tersebut.

Jankowski (2001) membagi bahan pelacakan menjadi tiga yaitu tracers, kimia \& pewarna (dye), serta bahan radioaktif. Prinsip ketiga jenis bahan pelacakan ini adalah sama yaitu memasukkan bahan pelacak pada sebagaian sistem aliran yang diperkirakan pada akuifer karst dan melakukan monitoring pada titik output atau keluaran dari sistem tersebut. Oleh karena sifat aliran di akuifer karst yang cepat, terutama pada conduit serta adanya kemungkinan kebocoran atau rumitnya jaringan sistem karst bawah tanah, maka untuk identifikasi daerah tangkapan dan keluaran pada sistem akuifer karst, tracer haruslah mempunyai syarat-syarat seperti tidak beracun, larut di air, dapat dilakukan dengan jumlah yang tidak terlalu banyak, resisten (tidak merubah reaksi kimia di air), tidak dapat terserap oleh batuan, tidak terpengaruh reaksi pertukaran ion, murah dan mudah dianalisis.

\section{Maksud dan Tujuan}

Studi ini dimaksudkan untuk mendapatkan gambaran yang lebih mendalam tentang jaringan hidrologi karst di daerah rencana eksploitasi baru dalam Narogong Plant PT. Holcim Indonesia.

Adapun tujuan dari studi ini adalah sebagai berikut:

1. Mengetahui potensi sumberdaya airtanah pada sebagian wilayah Narogong Plant

2. Mengetahui adanya sistem jaringan airtanah karst yang saling berhubungan 


\section{METODOLOGI}

\section{Alat dan Bahan Penelitian}

Alat yang digunakan untuk memperoleh data dalam penelitian ini antara lain adalah:

(1) Separangkat alat Current Meter

(2) Pita Ukur

(3) GPS

(4) Fluorometer

(5) Botol pelampung

(6) Seperangkat alat komputer untuk keperluan analisis dan penyusunan laporan (Microsoft Excel dan Arc Gis 9.3)

Kemudian bahan yang diolah lebih lanjut dalam penelitian ini berupa :

(1) Peta site plan dari quarry PT. Holcim Indonesia, Narogong Plant, Bogor, Jawa Barat

(2) Hasil inventarisasi kenampakan sinkhole, gua horizontal, gua vertikal, serta mata air di sekitar daerah penelitian.

\section{Data yang dikumpulkan}

Data yang dikumpulkan dalam penelitian ini meliputi:

(1) Data posisi absolut sinkhole, gua horizontal, dan gua vertikal

(2) Orientasi arah pelorongan dari kenampakan gua, sinkhole

(3) Orientasi arah aliran mata air

(4) Data debit aliran gua berair dan mata air di permukaan

(5) Data pendukung dari penelitian sebelumnya

\section{Cara pengumpulan data}

(1) Letak absolut kenampakan sinkhole, gua horizontal, dan gua vertikal

Letak absolut kenampakan tersebut dikumpulkan dengan cara survei langsung ke lapangan.

(2) Arah pelorongan dan arah aliran air dari gua berair, serta orientasi arah aliran mata air

Diketahui dengan survei lapangan disertai pencatatan langsung mengenai orientasi arah melalui peta yang sudah dimiliki sebelumnya.

(3) Data debit gua berair dan mata air di permukaan

Menggunakan velocity area method dengan current meter dan dengan botol pelampung sesuai dengan kondisi aliran dengan rincian sebagai berikut : 
a. Pengukuran dengan current meter

Prinsip pengukuran debitnya adalah kecepatan aliran diukur dengan menggunakan current meter, sedangkan luas penampang basah (A) ditetapkan berdasarkan pengukuran lebar permukaan air dan kedalaman air. Pengambilan titik pengukuran dengan current meter berdasarkan kedalaman air. Hal itu mengingat bahwa kecepatan aliran sungai tidak merata pada setiap kedalaman yang berbeda. Pemilihan jumlah vertikal yang akan diukur didasarkan pada bentuk dan ukuran penampang sungai, sifat aliran dan waktu yang tersedia. Pada sungai yang mempunyai dasar tidak teratur sebaiknya pengukuran dilakukan lebih rapat dari pada yang teratur. Dari pengukuran kecepatan pada masing-masing vertikal dapat dihitung debit pada masing-masing segmen.

b. Pengukuran dengan pelampung

Prinsip pengukuran dengan metode ini adalah kecepatan aliran diukur dengan menggunakan pelampung, luas penampang basah (A) ditetapkan berdasarkan pengukuran lebar permukaan air dan kedalaman air. Persamaan debit yang diperoleh adalah :

\section{$\mathbf{Q}=\mathbf{A} \times \mathbf{k} \times \mathbf{U}$}

Keterangan :

$\mathrm{Q}=$ debit aliran $\left(\mathrm{m}^{3} / \mathrm{dt}\right)$ :

A = luas penampang basah $\left(\mathrm{m}^{2}\right)$

$\mathrm{U}=$ kecepatan pelampung $(\mathrm{m} / \mathrm{dt})$

$\mathrm{k} \quad=$ koefisien pelampung

Nilai k tergantung dari jenis pelampung yang digunakan, nilai tersebut dapat dihitung dengan menggunakan rumus (Y.B. Francis) sebagai berikut:

$$
\mathbf{k}=\mathbf{1}-\mathbf{0 , 1 1 6}(\sqrt{ } \mathbf{1}-\propto \quad \mathbf{0 , 1})
$$

Keterangan :

$\propto \quad=$ kedalaman tangkai (h) per kedalaman air (d), yaitu kedalaman bagian pelampung yang tenggelam dibagi kedalaman air

(4) Data rekaman tracer test

Data rekaman yang dikumpulkan tersimpan dalam alat flurometer dengan waktu perekaman setiap 10 sekon. 


\section{Cara Analisis Data}

(1) Analisis Keruangan

Seluruh informasi yang bersifat spasial mengenai sebaran kenampakan baik berupa sinkhole, gua, maupun mata air dianalisis secara keruangan untuk memberikan informasi lebih detail mengenai luasan area yang diperuntukan untuk keperluan konservasi dalam Site Narogong Plant PT. Holcim Indonesia.

(2) Analisis Deskriptif

Diberlakukan pada seluruh data dan informasi yang diperoleh dalam penelitian ini sehingga seluruh tujuan penelitian dapat terjawab dengan jelas.

\section{HASIL DAN PEMBAHASAN}

\section{Potensi Sumberdaya Airtanah}

Sumberdaya airtanah di daerah karst memerlukan kajian khusus karena tidak semua lokasi dapat diketahui potensinya, hanya daerah tertentu saja menggunakan pendekatan sistem rekahan. Akumulasi potensi air bawah tanah di daerah karst akan banyak ditemukan pada pertemuan dari sistem rekahan karena air yang ada di permukaan akan dengan mudah masuk ke dalam tanah melalui rekahan yang ada hingga terakumulasi di bawah tanah, bahkan hingga menjadi aliran sungai bawah tanah.

\section{Mata air Cipintu}

Mata air Cipintu sebagai main object (objek utama) dalam kajian ini. Mata air Cipintu merupakan salah satu outlet dari airtanah yang keluar di perbukitan karst dalam area tambang Narogong Plant PT. Holcim Indonesia. Mata air Cipintu merupakan mata air karst yang keluar melalui sistem rekahan yang relatif cukup besar di bagian bawah perbukitan karst. Outlet mata air Cipintu dari luar terlihat seperti mulut gua, dan air yang keluar melalui mata air ini akan menjadi aliran air seperti sungai. Mata air Cipintu bersifat perennial (mengalir sepanjang tahun) namun fluktuasi debitnya relatif cukup tinggi. Saat musim penghujan, input air ke mata air ini termasuk cukup intensif terutama melalui sistem pelorongan yang relatif besar sehingga sering terlihat mata air menjadi agak keruh. Saat musim kemarau umumnya debit mengalami penurunan sangat drastis namun 
masih tetap ada aliran air disana. Kajian khusus diperlukan untuk mengetahui daerah imbuhan dari Mata air Cipintu.

Aliran air bawah tanah seperti yang keluar melalui Mata air Cipintu dapat didekati melalui sistem rekahan yang ada di permukaan serta saluran air di permukaan yang menuju bawah tanah seperti sinkhole atau ponor dan mulut gua (gua vertikal maupun gua horizontal). Sistem rekahan yang berukuran kecil akan mengimbuh air bawah tanah melalui tetesan-tetesan ornament gua (misal: dari tetesan stalaktit dan dinding gua) dan bergerak secara difusi, sedangkan rekahan yang berukuran besar dan sangat besar, seperti sinkhole dan gua akan mengimbuh airtanah melalui aliran dengan debit relatif besar dan bergerak melalui sistem pelorongan. Untuk itulah survei yang dilakukan pun dimulai dengan mengobservasi beberapa sinkhole dan mulut gua yang diasumsikan sebagai tempat aliran air masuk mengimbuh aliran airtanah.

Potensi debit air di Mata air Cipintu tercatat sebesar 18,55 liter/s. Pengukuran ini dilakukan dengan velocity area method yang menggunakan current meter. Kecepatan aliran air sebesar 14,9 cm/s. Debit air ini merupakan debit air sesaat yang diukur pada waktu tersebut. Debit air akan selalu berubah tergantung imbuhan yang masuk ke dalam sistem jaringan airtanahnya. Imbuhan akan selalu berubah tergantung ada tidaknya air hujan sebagai input utama airtanah disana. Air yang keluar pada outlet ini secara kualitas fisik sederhana masih berwarna jernih dan tidak berasa. Secara kimia nilai alkalinitas $\left(\mathrm{HCO}_{3}{ }^{-}\right)$sebesar 5,2 mmol/liter, hal ini masih sesuai dengan kadar alkalinitas air di karst dan masih memenuhi kadar kimia air yang dimanfaatkan untuk memenuhi kebutuhan domestik.

\section{Gua Berair}

Lokasi tambang terdapat satu gua berair. Gua berair ini tergolong gua yang relatif mudah untuk dimasuki dengan pelorongan gua yang relatif cukup besar. Gua berair ini berada di di dekat sistem perlembahan besar dengan arah pelorongan dari mulut gua yaitu barat daya-timur laut. Secara absolut, gua berair ini berada pada koordinat 48S 0714086; 9284155. Gua ini memiliki sistem pelorongan dominasi barat daya-timur laut dan selatan-utara. Panjang pelorongan gua ini dari mulut gua hingga ke bagian ujung gua \pm 138 meter. Terdapat dua sinkhole cukup besar di atas pelorongannya, yaitu di bagian tengah dan bagian ujung dari gua ini. Pada bagian ujung gua terdapat runtuhan batuan (rockfall) yang berasal dari dinding gua serta batuan di permukaan yang jatuh melalui sinkhole paling ujung. Aliran sungai bawah tanah yang berada pada gua ini muncul dari dari ujung belakang gua yang keluar dari bawah runtuhan batuan, yang kemudian pada ujung 
satunya (di bagian depan, dekat dengan mulut gua) masuk kembali ke dalam sistem rekahan yang tak terlihat.

Pelorongan gua berair hanya dapat diidentifikasi ke ujung paling belakang saja, sedangkan ke arah depan tidak dapat terlihat jaringan air bawah tanahnya. Pelorongan bagian paling ujung dari gua berair ini mendekati ke arah Gua-gua Sibayur, yang kemungkinan Gua-gua Sibayur menjadi daerah imbuhan dari aliran sungai bawah tanah di gua berair ini. Untuk mengetahui arah aliran sungai bawah tanah serta jaringan air bawah tanahnya ini diperlukan kajian khusus terkait penelusuran air yaitu menggunakan metode uji tracer (tracer test).

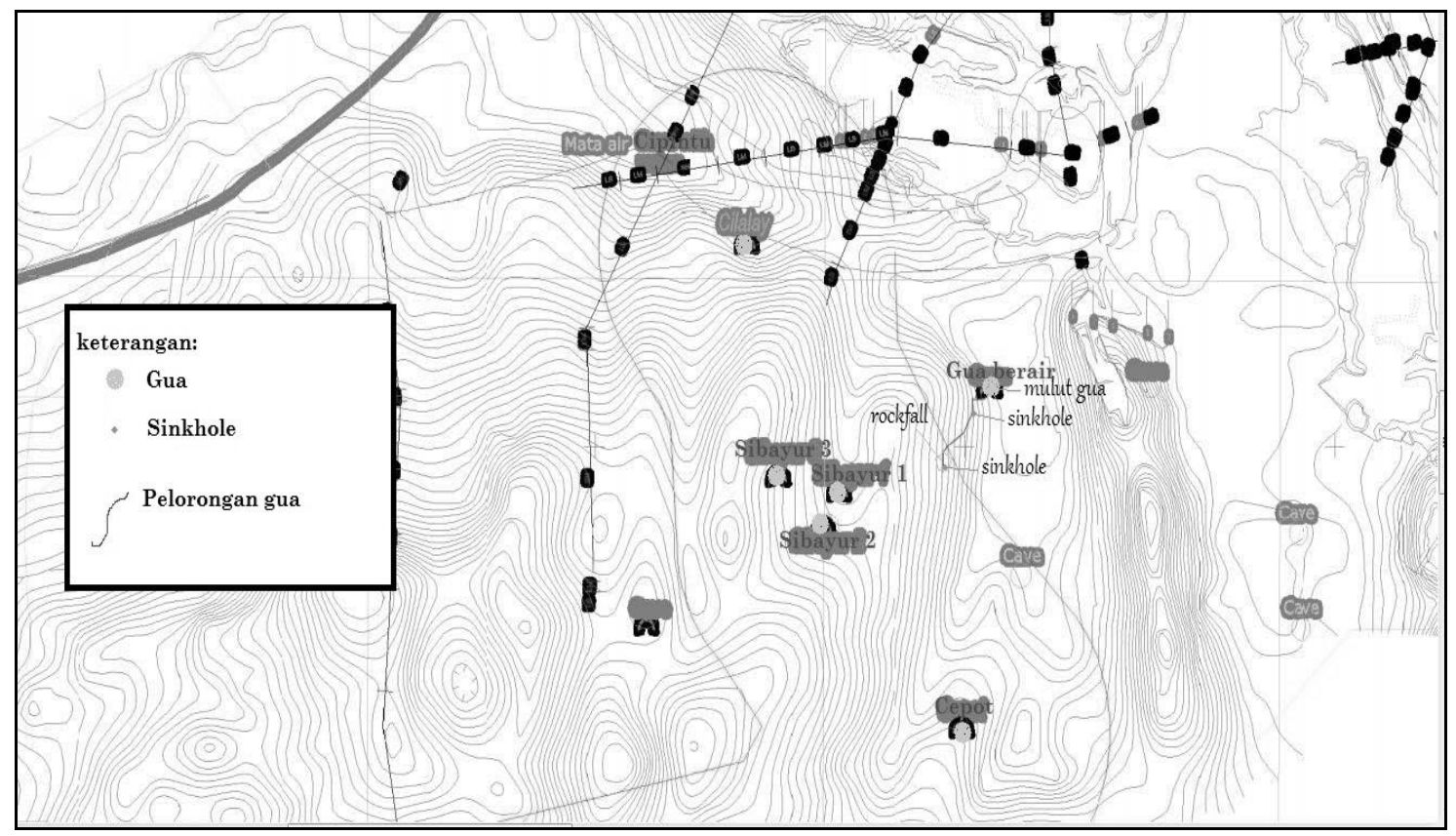

Gambar 2. Lokasi sebagian area tambang Narogong Plant

Potensi debit sungai bawah tanah dalam gua berair ini diukur menggunakan velocity area method menggunakan botol pelampung. Hasil pengukuran didapatkan debit sungai bawah tanah sebesar 14,8 liter/s. Kecepatan aliran air sungai bawah tanah sebesar 19,44 cm/s. Air sungai bawah tanah ini secara kualitas fisik sederhana masih berwarna jernih dan tidak berasa. Secara kimia nilai alkalinitas $\left(\mathrm{HCO}^{3}\right.$-) sebesar 6,6 mmol/liter, hal ini masih sesuai dengan kadar alkalinitas air di karst dan masih memenuhi kadar kimia air yang dimanfaatkan untuk memenuhi kebutuhan domestik.

\section{Gua dan sinkhole lain}

Gua x dengan koordinat 48S 0713930; 9283473. Gua ini merupakan gua yang berada di selatan dari gua berair. Gua ini merupakan gua vertikal yang berada di lereng perbukitan karst. Arah kemiringan lereng menuju ke arah timur. Gua x kemungkinan akan mengimbuh airtanah secara cepat karena 
sistem pelorongan berada di dekat permukaan tanah dan cukup besar. Limpasan permukaan saat hujan deras pun akan mengalir menuju ke arah utara yang kemungkinan pula akan mengimbuh aliran dari sungai bawah tanah di gua berair. Gua y dengan koordinat 48S 0713858; 9283359 merupakan sebuah sinkhole sebagai tempat aliran air permukaan masuk dan mengimbuh airtanah melalui sinkhole ini. Arah pelorongan di mulut gua terlihat berorientasi arah barat laut. Arah aliran air ini memungkinkan juga akan mengimbuh sungai bawah tanah di gua berair.

Gua Cepot dengan koordinat 48S 0713998; 9283682 merupakan gua yang berada pada lereng perbukitan di selatan gua berair dan sistem pelembahan besar. Gua ini merupakan gua vertikal dengan chamber besar di bagian dasarnya. Gua ini kemungkinan pun dapat mengimbuh airtanah hingga menuju ke sungai bawah tanah karena masih berada dalam satu kelurusan dengan gua berair. Kemiringan lereng pada lokasi Gua Cepot ini berorientasi pada arah timur laut. Limpasan permukaan dari daerah ini sekitar gua ini akan masuk melalui sinkhole yang berada di pelembahan besar di dekat gua berair.

Terdapat tiga buah sinkhole di daerah pelembahan besar, dekat dengan mulut Gua berair. Tiga buah sinkhole tersebut sebagai tempat aliran masuk terutama air dari aliran permukaan ataupun limpasan permukaan saat hujan deras terjadi di lereng perbukitan sekitar pelembahan besar tersebut. Ketiga sinkhole tersebut kemungkinan besar akan pula mengimbuh aliran sungai bawah tanah yang sama dengan yang ada di Gua berair.

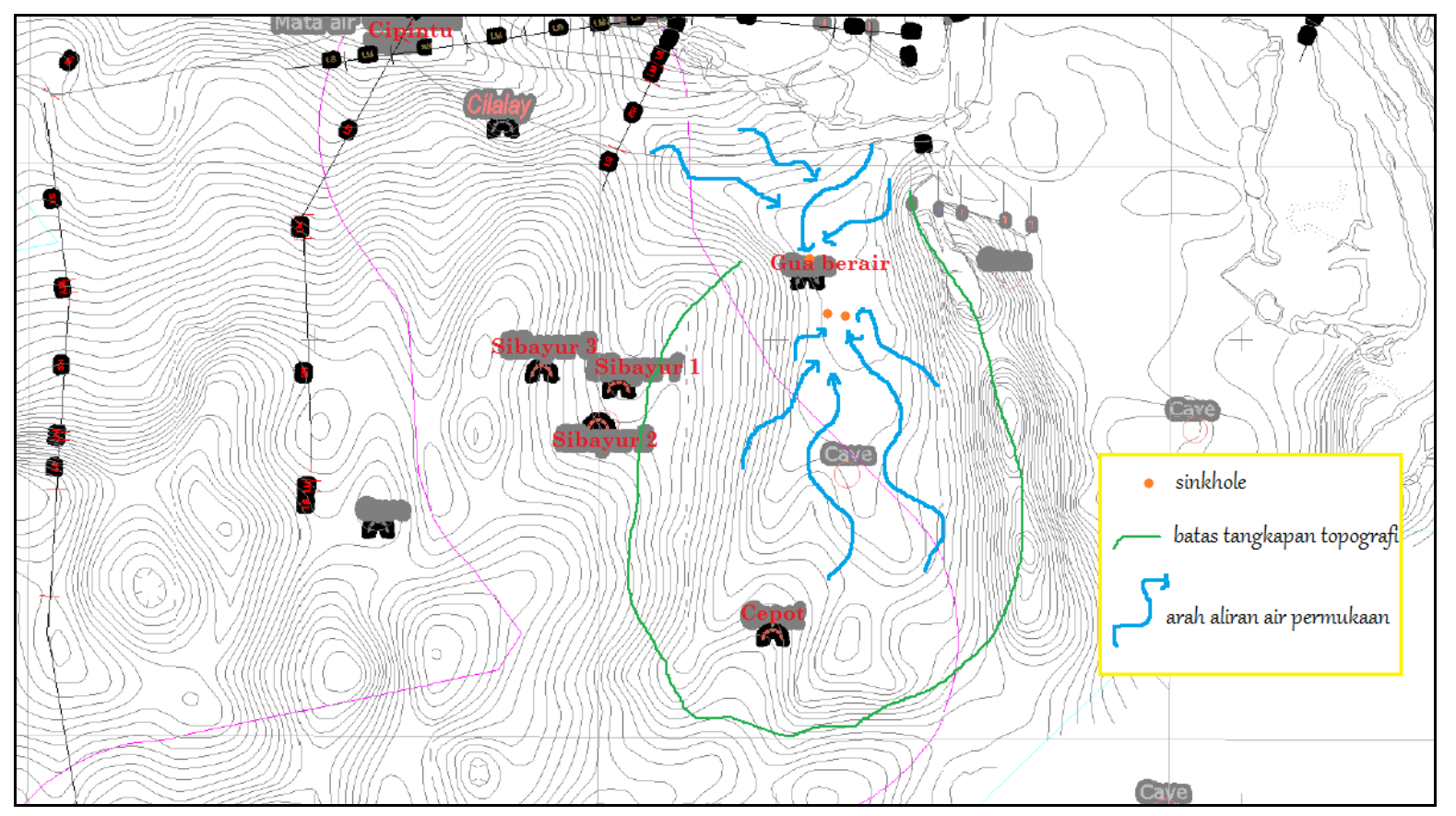

Gambar 3. Arah aliran air permukaan menuju ketiga sinkhole di pelembahan besar 


\section{Uji Tracer (Tracer Test)}

Tracer test dilakukan sebagai bentuk follow-up dari survei gua dan sinkhole yang ada di sekitar area tambang. Tracer test akan berguna mengetahui arah aliran airtanah walaupun tidak mengetahui sistem jaringan bawah tanahnya. Tracer test menggunakan pewarna eosin yang akan berwana hijau ketika bercampur dengan air. Tracer test yang dilakukan untuk mengetahui konektivitas aliran pada sistem Gua berair dan Mata air Cipintu. Tracer test dilakukan pada jam 12.15 dengan melepaskan sekitar larutan eosin ke dalam aliran sungai bawah tanah pada Gua berair. Akan tetapi hari pada jam sebelumnya yaitu sekitar jam 11.00 terlebih dahulu dipasang sensor fluorometer sebagai alat penangkap sensor pewarna yang terpasang pada Mata air Cipintu.

Secara kasat mata, pewarna mulai muncul pada jam 05.30 hari berikutnya. Hal ini berarti waktu tempuh yang dibutuhkan aliran air sungai bawah tanah dari Gua berair untuk sampai ke Mata air Cipintu $\pm 17,5 \mathrm{jam}$. Terekam pula pada sensor flurometer bahwa eosin terdeteksi melewati alat sekitar jam 05.30. Hal ini mengindikasikan adanya konektivitas antara Gua berair dengan Mata air Cipintu dan sesuai dengan hipotesa awal yang dibangun berdasarkan hasil interpretasi di lapangan.

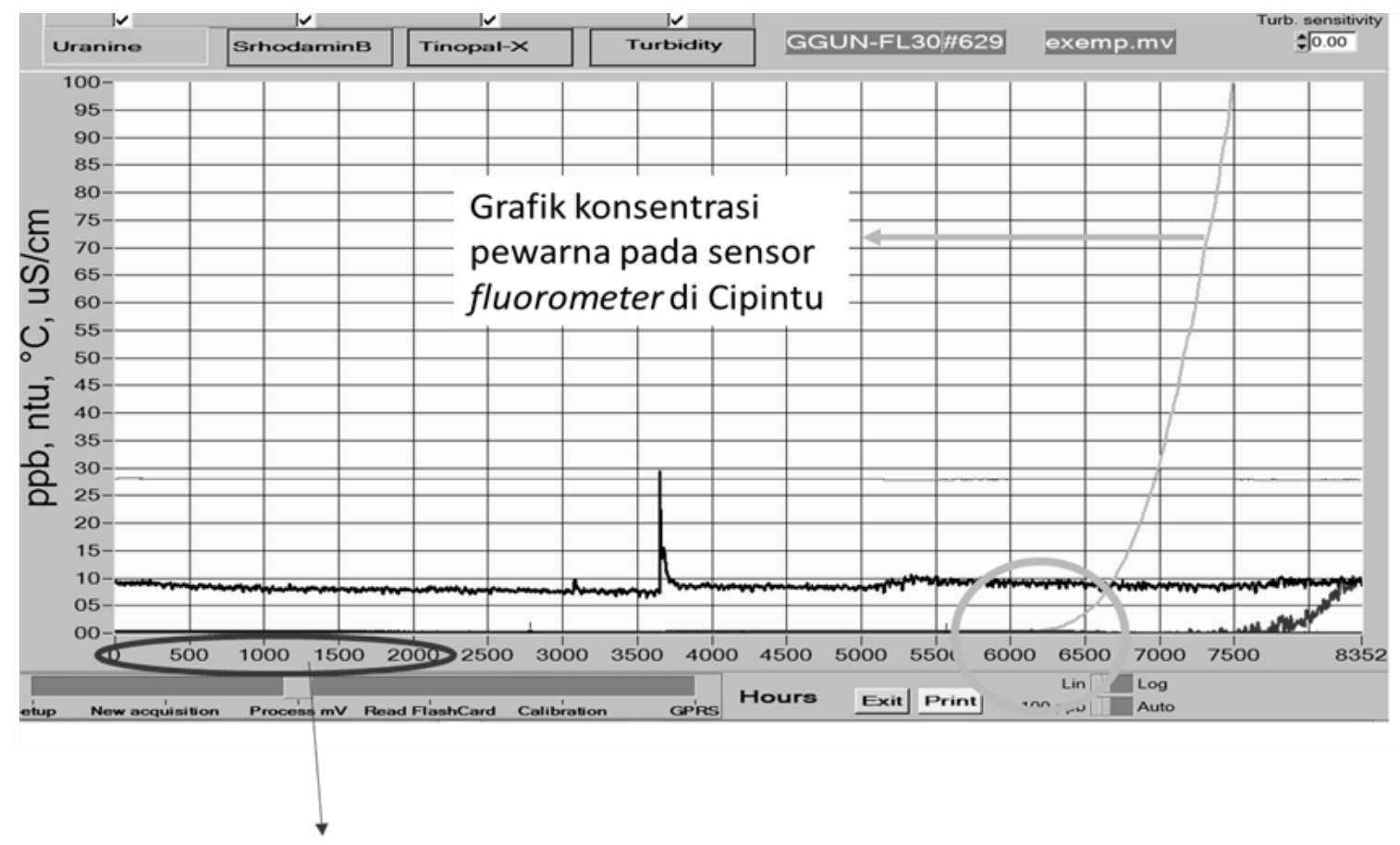

Banyak data

Gambar 4. Grafik pembacaan pada sensor fluorometer 


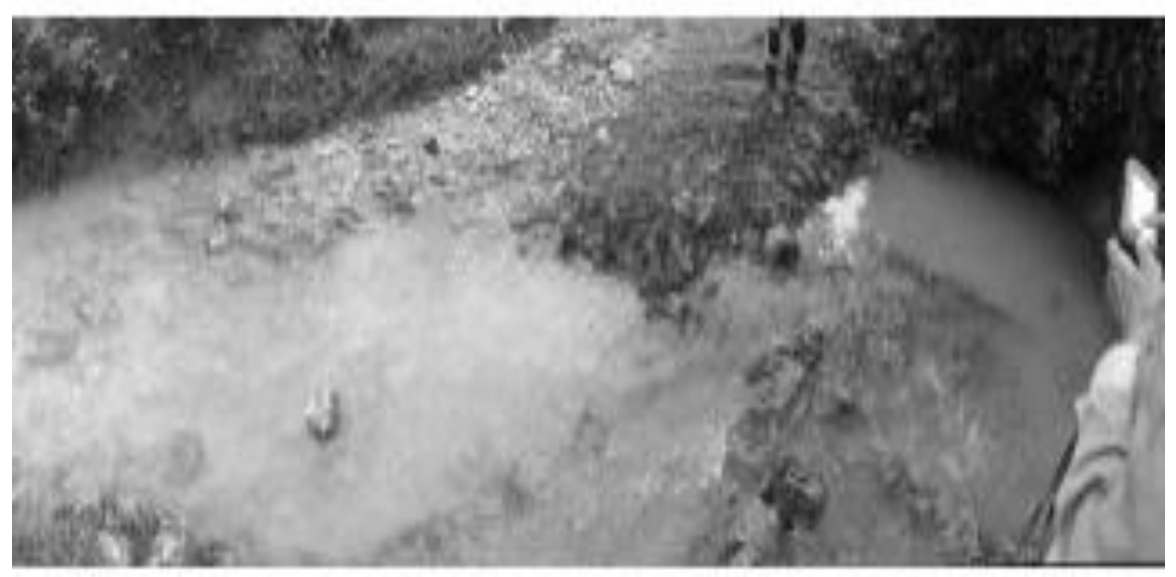

Gambar 5. Pemunculan pewarna pada outlet Mata air Cipintu setelah 23 jam dari waktu pelepasan eosin

Pewarna juga teridentifikasi muncul pada mata air kecil yang berada di sebelah timur mata air Cipintu dengan jarak \pm 200 meter. Mata air kecil ini kemungkinan merupakan bocoran dari mata air Cipintu ke arah timur dan masi merupakan satu sistem dengan Mata air Cipintu sehingga pewarna eosin pun muncul pada mata air ini. Pemunculan warna pada mata air ini waktunya relatif berdekatan dengan mata air Cipintu karena memang jarak pemunculannya di permukaan antar keduanya tidak terlalu jauh.

\section{KESIMPULAN DAN SARAN}

\section{Kesimpulan}

Berdasarkan hasil pengukuran lapangan potensi debit air di Mata air Cipintu sebesar 18,55 liter/s. Debit air ini merupakan debit air sesaat yang diukur pada waktu tersebut dan selalu berubah tergantung imbuhan yang masuk ke dalam sistem jaringan airtanahnya. Imbuhan akan selalu berubah tergantung ada tidaknya air hujan sebagai input utama airtanah. Air yang keluar pada outlet ini secara kualitas fisik sederhana masih berwarna jernih dan tidak berasa. Secara kimia nilai alkalinitas $\left(\mathrm{HCO}_{3^{-}}\right)$sebesar 5,2 mmol/liter, hal ini masih sesuai dengan kadar alkalinitas air di karst dan masih memenuhi kadar kimia air yang dimanfaatkan untuk memenuhi kebutuhan domestik.

Sistem jaringan airtanah karst antara Gua berair dengan mata air Cipintu saling berhubungan, hal ini terlihat secara kasat mata pewarna mulai muncul di mata air Cipintu. Waktu tempuh yang dibutuhkan aliran air sungai bawah tanah dari Gua berair untuk sampai ke Mata air Cipintu \pm 17,5 jam ditunjukan dari hasil perekaman pada sensor flurometer bahwa eosin terdeteksi melewati alat tersebut. Pewarna juga teridentifikasi muncul pada mata air kecil yang berada di sebelah timur 
Mata air Cipintu dengan jarak \pm 200 meter. Mata air kecil ini kemungkinan merupakan bocoran dari Mata air Cipintu ke arah timur dan masih merupakan satu sistem dengan Mata air Cipintu sehingga pewarna eosin pun muncul pada mata air ini. Pemunculan warna pada mata air ini waktunya relatif berdekatan dengan Mata air Cipintu karena memang jarak pemunculannya di permukaan antar keduanya tidak terlalu jauh.

\section{Saran}

Konservasi daerah karst diperlukan agar ekosistem daerah karst relatif tetap terjaga dengan baik, terutama terkait dengan sistem hidrologi di daerah karst. Pengelolaan daerah karst yang kurang baik dapat mengganggu stabilitas sistem hidrologi bawah tanah di karst. Jika terjadi kerusakan di permukaan, sehingga mengganggu sistem rekahan alami yang ada maka input air ke bawah tanah akan berkurang pula, lebih parah lagi input air bawah tanah akan hilang selamanya. Daerah konservasi difokuskan pada kemungkinan daerah imbuhan dari mata air Cipintu, termasuk di dalamnya sistem rekahan, sinkhole, mulut gua, dan pelorongan gua sebagai tempat air masuk dan air lalu menuju ke outlet mata air Cipintu.

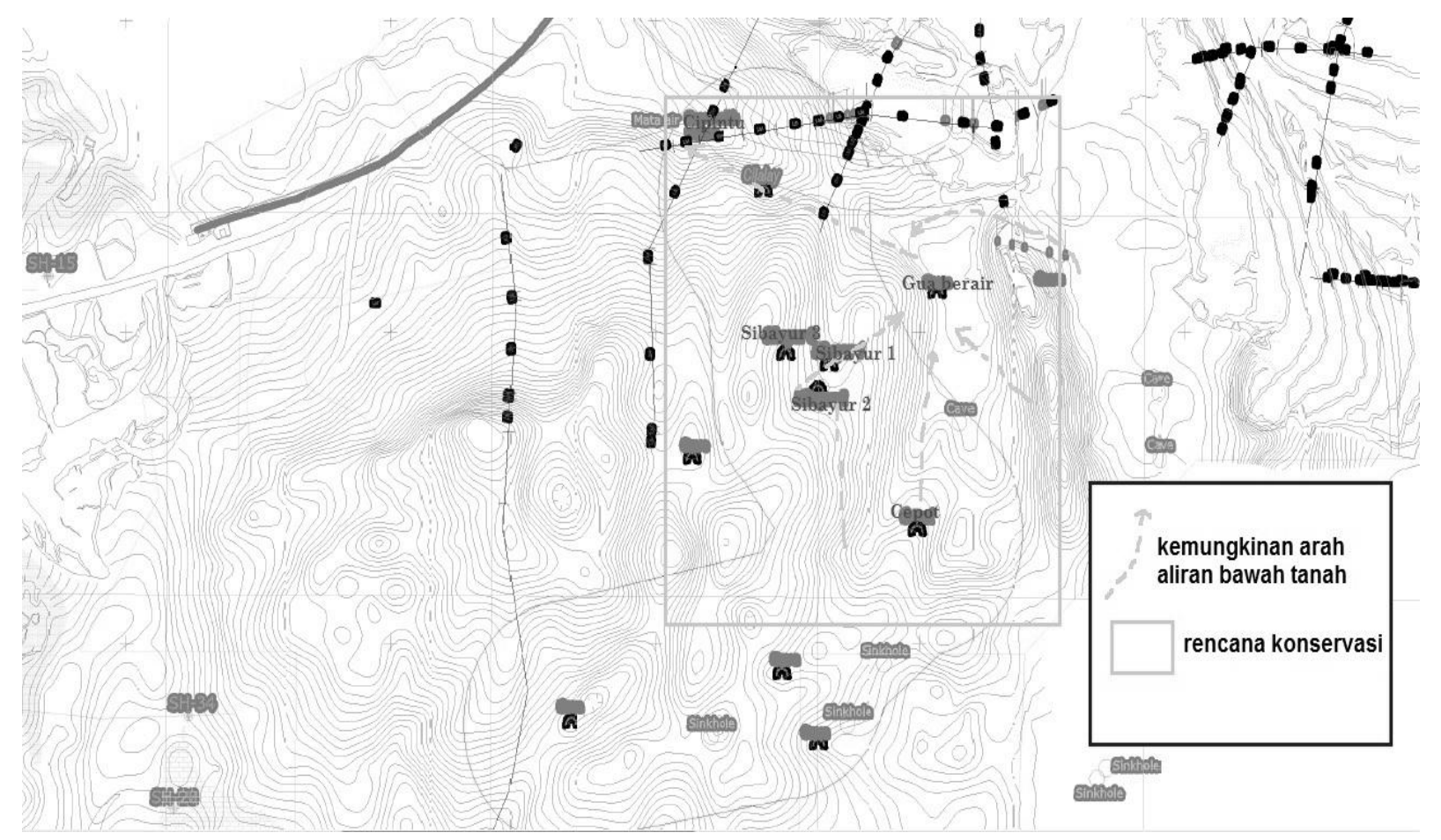

Gambar 6. Arah aliran bawah tanah dan rencana konservasi

Sistem jaringan air bawah tanah dari Gua berair-Mata air Cipintu serta mata air kecil sebelah Cipintu merupakan sistem input-output air bawah tanah sehingga area tersebut perlu dikonservasi sehingga kuantitas dan kualitas Mata air Cipintu masih relatif terjaga dengan baik. Sinkholesinkhole yang berada pada sistem pelembahan besar di sebelah mulut Gua berair merupakan daerah 
imbuhan dari sungai bawah tanah yang mengalir menuju Mata air Cipintu sehingga lembah beserta perbukitan di bagian timur selatan dan utara perlu dikonservasi agar input air tetap berlangsung. Gua-gua Sibayur, Gua Cepot serta sinkhole yang berada di sekitarnya masih merupakan daerah konservasi yang perlu dijaga agar imbuhan air menuju sungai bawah tanah yang mengarah ke Mata air Cipintu, baik secara langsung maupun tidak dapat selalu terjaga dengan baik.

\section{DAFTAR PUSTAKA}

Acworth, R.I., 2001, Electrical Methods in Groundwater Studies, Short Course Note, School of Civil and Environmental Engineering, University of New South Wales, Sydney, Australia

Bonacci, O., 1990, Regionalization in Karst Regions, Proceedings of the Ljubljana Symposium, April 1990, IAHS Publ. no. 191, 1990

Ford, D. and Williams, P., 1992, Karst Geomorphology and Hydrology, Chapman and Hall, London

Goldscheider, Nico and Drew, 2010, Karst and Alpine Hydrogeology. Karlsruhe Institute of Technology, Institute of Applied Geosciences

Jankowski, J., 2001, Hydrogeochemistry, Short Course Note, School of Geology, University Of New South Wales, Sydney, Australia

Linsley, R.K., Kohler, M.A., Paulhus, J.L., 1975, Hydrology for Engineers. 2nd. Ed. Mc Graw Hill Kogakusha Ltd. Tokyo, Japan

MacDonalds and Partners, 1983, Greater Yogyakarta - Groundwater Resources Study. Vol 1: Main Report. Yogyakarta, Directorate General of Water Resources Development Project (P2AT)

Todd, D.K., 1980, Groundwater Hydrology, 2nd Ed. John Wiley \& Sons

White, W.B., 1988, Geomorphology and Hydrology of Karst Terrain, Oxford University Press, New York 